\title{
All-around care for patients with Chagas disease: a challenge for the XXI century
}

\author{
Wilson de Oliveira Jr \\ Ambulatório de Doença de Chagas e Insuficiência Cardíaca, Pronto Socorro Cardiológico de Pernambuco, Hospital Universitário \\ Oswaldo Cruz, Universidade de Pernambuco, Rua dos Palmares s/n, 50100-060 Recife, PE, Brasil
}

\begin{abstract}
In 1987, the University of Pernambuco's Oswaldo Cruz Hospital in Recife, Brazil opened its Chagas Disease and Heart Failure Outpatient Clinic with the aim of providing its patients all-around care through adoption of a biopsychosocial model of care. All-around care involves caring for the patient as a whole human being in the context of the biological, psychological and social factors present, which are an inherent part of the human condition. One prerequisite for the proposed model of care is the participation of a multidisciplinary team of trained technical staff committed to this framework. Although the main focus of the service is on care, teaching and research are also an important part of its work. The Pernambuco Association of Chagas Disease Patients is guided by the same model of care and has been carrying out educational activities relating to the disease, its treatment and support for patients and family members for several years. This Association plays an important role in advocating to public authorities on behalf of patients. The accumulated experience of the past 22 years has shown us that a broad vision of health care can help clinicians and policy makers to make decisions that are more in tune with the everyday reality of the patient, which in turn has a positive impact on adherence to treatment and quality of life.
\end{abstract}

Key words: Chagas disease - all-around care - biopsychosocial model

Chagas disease, which was discovered a century ago in April of 1909 by the Brazilian researcher Carlos Chagas, is still a serious public health problem in Latin America, with repercussions around the world. In describing it, Chagas addressed its etiological agent Trypanosoma cruzi, transmission mechanisms and natural reservoirs, in addition to its clinical manifestations. Chagas pointed to the social implications of the disease, since it primarily afflicts populations of low socio-economic status and results in high levels of morbidity and mortality (Chagas 1909).

A visionary and deeply committed humanist, Carlos Chagas warned of the biosocial implications of the genesis, evolution and continuation of the disease, which, thus, require treatment and control approaches that go beyond the field of biology. Unfortunately, to date, there are still very few publications that deal with the disease from this perspective (Dias \& Dias 1979, Briceño-Leon 1990, Oliveira 1997).

In its primitive form, infection is restricted to the countryside environment, where it attacks small and medium-range mammals and is transmitted through triatomines. It thus has the epidemiological characteristics of an enzootic rural disease, which, due to the invasion of its natural habitat by human beings, has gradually be-

Corresponding author: woliveirajr@uol.com.br Received 31 March 2009

Accepted 8 June 2009 come an anthropozoonosis. With the domestication of some species of triatominae, human Chagas disease has also become a zoonosis. In the middle of the XX century, the model of economic development, remembering that development is not synonymous with growth, adopted in Brazil contributed enormously to rural depopulation and the migration of considerable numbers of individuals to the big cities in order to find better employment opportunities. This migration also gave rise to the migration of Chagas disease patients from the countryside to the city. In the past two decades, considerable progress has been made in controlling Chagas disease, through not only activities that control vectors, but also activities that involve controlling its transmission via blood transfusion, which constitutes a positive indicator of the efficacy of the measures adopted. Inasmuch as action to contain the spread of Chagas disease is concerned, some challenges remain, including the following: (i) caring for the large numbers of individuals with chronic Chagas disease who need to be treated and kept under observation; (ii) maintaining systematic vector control programs; (iii) encouraging and supporting the emergence of new drugs that are more effective and less toxic for etiological treatment of chronic cases and (iv) encouraging teaching and research and other strategic action, as argued by Coura (2007).

Finally, there is a need to ensure that the scientific community and society at large remain alert to the fact that Chagas disease has not been eradicated, only controlled, and it, therefore, must remain a priority for public health policy. Another factor that has been a source of concern to the world sanitary community is the socalled globalisation of Chagas disease, due to the substantial amount of emigration from endemic areas. On the other hand, it is evident that there is a need to equip 
and train health workers to deal with patients clinically. Although the biological understanding of the various ways in which Chagas disease manifests itself is of the utmost importance, it is not sufficient. In continuing to address a disease deeply rooted in social and cultural factors, such as poverty, ignorance, inadequate sanitary conditions and so forth, through a care model that exclusively addresses the biological aspects of the disease, the psycho-social and cultural aspects that are clearly involved in the complex process of contracting that disease have been overlooked (Coura 1985, Dias et al. 1994, 2007, Dias 2000, WHO 2002, 2007, DNDi 2008).

Given the specific features of patients with Chagas disease, we shall address factors related to the biological model of care that, at present, is universally employed: the biomedical model. We will then submit a proposal for all-around care, which is a biopsychosocial model of patient care.

\section{The biomedical model}

Over the years, science, in general, and medicine, in particular, has come to adopt cartesian paradigms that have contributed to a change in the attitude adopted by doctors with regard to their patients. At first, in view of the inexistence of complementary diagnostic methods, the health professional was "forced" to investigate his or her diagnostic hypothesis using signs and symptoms observed in or reported by the patient.

In the VI and VII centuries, with the rise of the empirical inductive rational method of Bacon, Newton's mechanics and the analytical method of Descartes, modern science emerged. Gradually, human beings came to be seen as quantifiable parts and relations not susceptible to measurement came to be seen as having a secondary value in the investigative process. In 1910, with the publication of the Flexner report in the United States, the biomedical model, which established a biomedical view of the individual, gained ground and came to be used universally, resulting in profound changes in the way medical schools were structured (Fontes 1999).

Medicine has, for a long time, been amiss in terms of viewing the individual as a unique single being made up of body and mind, even in light of Freud's discoveries regarding the human unconscious and its possible influences on the organic whole (Fontes 1999).

In underestimating socio-anthropological variables and seeing them from a purely biological perspective, doctors are led to transform themselves into mere treaters of disease, rather than people who care for individuals (Siqueira 2002).

This biomedical model has a direct effect on the patient-doctor relationship, causing the disease to be seen as more important than the patient, and thereby establishing an "artificial" dualism of body and mind.

Although there can be no doubt as to the value of adopting the scientific biomedical model, the human being has been "reified" in the process. The central problem with this model resides not in any kind of intrinsically malignant nature, but in the fact that it is too restricted in its explanatory power and, thus, puts significant obstacles in the way of effective medical practice.
The biomedical model neglects to view the individual as an all-around human being and thereby fails to see the patient within his or her social, psychological, cultural and ecological circumstances (Oliveira 2005a).

With the loss of the human perspective in medicine, disease has come to be seen as a mechanical disorder of the organs that needs to be fixed, establishing a mind/ body dualism and transforming medical science into an activity geared exclusively towards the body. The doctor, thus, becomes little more than a mechanic. This is characteristic of the mechanistic view of modern-day medicine, according to which the doctor should concentrate his attention on the disease, not on the patient (Feinstein 1972, Oliveira 2005a).

\section{The biopsychosocial model}

The clinical physician George Engel, dissatisfied with the model of care that was widespread at that time, proposed a medical care method centred on a systemic point of view that incorporated behaviour into its understanding of human disease. Thus, the biopsychosocial model of disease was born. The model was the fruit of the general theory that systems interact with and impact one another, which can be seen when observing that the existing subsystems within the biopsychosocial model are interrelated (Engel 1977).

The biological aspects of the biopsychosocial model emphasise the anatomical, organic, molecular and cellular substrates of disease; the psychological aspects highlight the psychodynamic, motivational and personality features that are related to the experience of or reaction to the disease; and last, but not least, the social aspect covers the cultural, environmental and domestic factors that influence both the way a pathology manifests itself and the way a patient lives with a disease (Engel 1980).

According to Engel's model, "all" of these systems are directly or indirectly affected by the process of becoming ill and are related to one another. It is worth noting that Engel's model does not claim that disease is a direct result of the psychological or socio-cultural background of an individual, but rather encourages us to view disease and its treatment in a way that goes beyond the field of biology alone (Engel 1987).

In the biopsychosocial model, the doctor-patient relationship is a fundamental component. Therefore, every doctor should not only recognise the biological features of the patient, i.e., symptoms and organ functioning, but also be familiar with the psychological and socio-cultural factors that impact the process of becoming ill (Siqueira 2002).

Factors such as the presence of external support for the sick individual (e.g., in the home, in the workplace, in the community), the socio-economic circumstances of the individual, and the identification of stress and/ or protective factors in the various environments that the individual encounters may interfere with a patient's capacity to cope with the disease. Thus, a patient cannot be reduced to a diseased organ, a tendency which is a reflection of the sickness of the geopolitical system in which it occurs. This broader view - which goes be- 
yond biology - can help decision-makers working on the ground. Each individual lives his or her disease in a singular manner.

Thus, while medicine based on empirical evidence is necessary, in view of its importance and benefits, it alone is not a sufficient guide for decision-making, diagnosis and/or treatment. Other factors must be taken into account to avoid inflexible decisions that are based solely on scientific knowledge, although such knowledge should not be excluded from decision-making (Siqueira 2002).

In short, use of the biopsychosocial model requires that practitioners take a broader view of the human being as a way of modifying the way medicine is currently practiced.

\section{The psychosocial features of Chagas disease}

Carlos Chagas, in describing this disease 100 years ago, had already noticed the enormous causal effect of social factors on the origin and development of the disease. Despite the evident need for a more wide-ranging approach to Chagas disease, most studies, unfortunately, continue to give priority to biological factors alone, while ignoring others. It should be born in mind that the urban population of Chagas disease patients continues to show the same psychosocial, economic and cultural characteristics as those living in rural areas, since in both situations there are many common determining factors: poverty, ignorance, low levels of schooling, lack of employment, malnutrition and inhumane housing conditions. In fact, the disease is just one more factor exacerbating an already grievous and worrisome situation. On the other hand, the reality of the urban jungle leads to further social exclusion of people from the countryside, which aggravates the disease, especially among those who have chronic Chagas cardiomyopathy (Oliveira 1991). In these cases, exposure to strenuous physical effort, as a result of a lack of professional qualifications, in combination with malnutrition, smoking, alcoholism, poor medical care and other factors creates a fertile ground for the emergence of co-morbidities and a worsening of the clinical condition of the patient. The socio-economic impact of the disease is not restricted to the patient, but is also strongly reflected in the nuclear family. Loss of parents at an early age frequently leads to children dropping out of school to work to support their families. Chagas disease - in its cardiomyopathic forms - has a strong social and economic impact, owing to early retirement, long periods of sick leave and low productivity. Another important factor to consider is the high cost of the disease both for the health services, as it requires frequent hospitalisations, and for the family budget, which must cover the cost of medication. A disease manifests itself in and is seen to afflict individuals, but it also has an impact on the collective, since, although being sick is one of the most private human experiences, it is something that manifests itself most clearly in society at large. In psychological terms, it causes alterations in the way individuals work, produce, think and relate to their families and the rest of society, thereby leading to changes in patterns of behaviour. These are not always voluntary in nature, but imposed upon the individual by the disease. In chronic cardiomyopathies, including those induced by Chagas disease, psychological disorders are more clearly apparent, especially in view of the symbolism that surrounds the heart, understood by society at large as the organ that makes the difference between life and death (Caprara \& Franco 1999, Oliveira 2005b). In Chagas patients, depressive disorders find fertile ground in which to thrive, both because of the stigmatising nature of the disease and because of the limitations it imposes on the independence of the individual. Patients with the serious form of the disease, the one in which heart failure (HF) occurs, may experience severe psychological problems, especially those relating to the fear of sudden death. On the other hand, those without symptoms, who have the so-called indeterminate form of the disease, may experience psychological problems stemming from the fact that they see themselves as carriers of something known as "Chagas Evil", for which there is little in the way of cure. It is not rare to find whole families with this disease; and in each member of the nuclear family, the disease may manifest itself in different forms and with varying degrees of severity. Living with the disease, which may mean living with a history of sudden death in the family, heart pacemaker implants and frequent stays in hospital, may trigger psychological changes of varying degrees. The social causes of Chagas disease and its psychological repercussions are of such magnitude that it is impossible to broach them without considering the psychosocial features that accompany the development of the disease. In fact, we can no longer go on dealing with a complex problem in such a simplistic and linear fashion. The degree of complexity involved in the process of a Chagas patient falling sick necessitates an approach that goes beyond the disease itself, which, as mentioned above, is frequently seen as a purely organic entity and a target for a biologising approach. This reductionist point of view is insufficient to deal with Chagas patients, as psychosocial aspects are clearly involved in the pathological condition of these patients. These should not be neglected.

\section{The Chagas disease and Heart Failure Outpatient Clinic at the Oswaldo Cruz University Hospital - Procape/UPE: a care proposal}

Approximately 22 years ago, the Chagas disease and Heart Failure Outpatient Clinic was set up at the Oswaldo Cruz University Hospital/UPE with a view to providing more humane care, greater adherence to treatment and a subsequent reduction in morbidity and mortality among Chagas disease patients. This clinic later became a referral centre for the whole state of Pernambuco. In view of the multifactorial nature of the genesis and evolution of Chagas disease for patients, one prerequisite of the initial proposal, which has been built on over the years, was to provide all-around multidisciplinary care supported by a multiprofessional team that is well trained and shares the same approach to care. Multidisciplinary approaches are now recognised to be the best form of care for patients with chronic diseases. Our experience has shown this to be a fundamental tool in optimising adherence to treatment with a consequent reduction in 
the number of relapses and repeat stays in the hospital. It also improves quality of life, with a positive impact on morbidity and mortality rates. By setting up a service specifically aimed at Chagas disease and HF carriers, we aimed to address the specific features and multiple needs that accompany these pathologies. Initially, the care offered was solely biological in nature. However, given the complexity of the patients' conditions, it became clear that there was a need to incorporate other professionals into the team, thus broadening the scope of care and providing the groundwork for a multiprofessional team model. Despite the difficulties encountered, new professionals gradually came to embrace the cause and a team was formed that included cardiologists, a social worker, a psychologist, a nurse and a nutritionist. More recently, with the advent of the stem-cell implant therapy project for patients with chronic Chagas cardiomyopathy, the following professionals have also joined the team: a specialist in haemodynamics, a haematologist and a molecular biologist. Each member of this multidisciplinary team has a distinct role, although all members interact with each other. Team members attend a weekly clinical meeting to present reports or listen to a guest speaker talk about a relevant subject (Oliveira 2005a, b).

Cardiologist - The doctor in charge of the Chagas Disease and Heart Failure Outpatient Clinic is responsible for receiving the referred patient, whether it be for primary care, haemotherapy or other health services. Based on a clinical-epidemiological amanuensis and complementary medical examinations, a diagnosis is established and a course of treatment, pharmacological or not, is decided upon. The presence or not of comorbidities is also established. Wherever possible these are treated by the same service and, when not, patients are referred to specialists. It is important that there be a good, sympathetic and friendly relationship between the doctor and the patient and his or her family. Wherever possible, the patient continues to see the same doctor to facilitate bonding and consequent adherence to treatment. Apart from care, the doctor is also responsible for the coordination of the service and for providing support for other team members where necessary.

Nurse - The nurse plays a fundamental role in accompanying Chagas disease and HF patients. In particular, at our facility, the nurse is responsible for maintaining frequent contact with the patient from the very start of treatment; monitoring signs and symptoms that indicate early relapse; controlling body fluid, especially in patients with HF; educating patients and their families about the disease and the more common co-morbidities; managing interactions between the various members of the multidisciplinary team; keeping track of referrals and updating the patient records database.

A consultation with the nurse generally occurs immediately after one with the doctor and provides an opportunity to offer advice regarding medication and other forms of treatment, thereby strengthening the bond between the patient and the team. The nurse also has a permanent channel for dialogue with the patient through the
"Dial Heart Failure" service, which serves as a tool for easing doubts regarding treatment, referring emergencies and so forth.

Nutritionist - Nutrition is another important factor when working with patients in HF. The nutritionist works with the patient through evaluation, diagnosis of nutritional status, planning, prescription and monitoring. An evaluation of the patient's diet or nutritional amanuensis provides the nutritionist with information regarding the quantity and quality of food that the patient consumes on a daily basis, along with the patient's likes and dislikes and any food allergies they may have. One factor that should be present when providing guidance on diet and nutrition is the socio-economic, cultural and environmental background of the patients. This helps the nutritionist to design a feasible diet, thereby contributing to the patient's adherence to the new dietary regimen. The composition of foodstuffs should be made clear, especially in the case of sodium content, above all in processed foods. The nutritionist also explains the difference between "diet" and "light" food. The nutritional guidance should be planned as a result of a previously requested biochemical evaluation during the medical consultation. Depending on the results of these biochemical tests, it may be necessary to carry out a more specific dietary intervention that involves restrictions on certain kinds of food.

Psychologist - The approach to psycho-emotional issues in patients with Chagas disease and HF is one of the main pillars of the biopsychosocial model of care. The psychological impact of the disease is large and includes the gradual loss of physical abilities and growing dependence on family members (even among those who care for themselves in the most serious cases), the fear of imminent death, frequent stays in hospital and so forth. Thus, the psychologist is an indispensable member of any multidisciplinary team that works with this patient population. These factors may lead to considerable emotional overloads that result in anxiety and depression, which may contribute further to non-adherence to treatment. The main functions of the psychologist in the multiprofessional team at the Chagas Disease and Heart Failure Outpatient Clinic include evaluation and treatment of the psycho-emotional factors that are impairing the patient's quality of life, such as level of stress and relationships with family members, friends and work colleagues. Care for families aims to understand their dynamics and identify sources of anxiety that may destabilise the patient emotionally. The psychologist works at the outpatient clinic with individuals and/or groups. The psychologist is also responsible for identifying the most serious cases of psychological disorder and referring these to a psychiatrist, especially when medication may be necessary.

Social worker - Socio-economic factors contribute considerably to the genesis and evolution of Chagas disease. As this is a pathology that primarily afflicts people living in extreme poverty, the social worker needs to identify factors that may hinder the course of treatment, 
such as housing and sanitation conditions, means of transport to the treatment centre, level of schooling, availability of financial resources to purchase medicines and employment and welfare status. Once the socio-economic conditions of the patient have been established, measures are taken to minimise the impact of extreme poverty on the patient and the disease. Social work, in combination with the contribution of the Chagas Disease and Heart Failure Patients Association, aims to provide basic needs so that treatment can be followed. This may include provision of basic foodstuffs, bus fares and medication.

\section{The Chagas disease and Heart Failure Outpatient Clinic: all-around care, teaching and research}

The outpatient clinic is divided into two sections, one for caring for patients with Chagas disease, in its various stages and various manifestations, and a second for patients with more advanced HF, whether it is the result of Chagas disease or not. In addition to symptomatic and etiological treatment, the outpatient clinic also offers the possibility of installing pacemakers and/or cardiodefibrillators in patients who need them. The Chagas patients attending the clinic tend to be adults, between the ages of 30 and 60 years, are mostly female, come from rural areas or from the Metropolitan Region of Recife, are living in poor socio-economic conditions and have very little in the way of schooling or vocational education. Once selected by the outpatient clinic, the patient takes blood serum tests to confirm the diagnosis, along with an electrocardiogram and a chest X-ray to determine the extent of heart damage caused by the disease. Depending on the degree to which the heart or digestive system has been damaged, there will be a complementary diagnosis to determine the most adequate course of treatment and to identify any possible associated co-morbidities.

The staging of the disease will also determine how often the patient is to come to clinic. Patients with the indeterminate chronic form of the disease who have received a favourable prognosis for this condition should attend the clinic every six months or once a year. Such patients are also instructed to visit the clinic if there is any change in their condition (such as the appearance of symptoms) for evaluation and treatment, if needed. Patients with heart disease, depending on the classification of their functional capacities and associated comorbidities, are seen as frequently as their condition requires. Patients with a functional capacity classification of I or II, according to the New York Heart Association (NYHA), with few symptoms, are scheduled for quarterly visits. More seriously ill patients, with functional capacity classification of III or IV (NYHA) with serious impairment of their functional capacity need more frequent multidisciplinary supervision, varying from once a fortnight to once a month, to make adjustments to their course of treatment.

Experience has shown us that it is the seriously ill patients who benefit most from multidisciplinary care. In such cases, this approach is more cost-effective. The service offers the possibility of referral, emergency treatment, hospitalisation and epidemiological evaluation of other cases of Chagas disease in the family. The principal objective of teamwork, especially when dealing with chronically ill patients, as in the case of Chagas disease, is to allow for more interaction between members of the team, the patient and the patient's family, thereby providing a better understanding of the disease and a higher level of adherence to treatment. The participation of patients and their families is the lynchpin of any multidisciplinary approach to chronic diseases. In fact, it is impossible to achieve the proposed aims when this is absent. This approach presupposes that there is active participation in the treatment process. The whole treatment plan is, in fact, drawn up with the patient rather than for the patient. Meetings of team members and patients are periodically held to consolidate information and the language used is clear and objective to ensure that any doubts are dispelled. It has been observed in these groups that most of the queries brought up relate to communication difficulties arising from formal contact between the doctor and patient. When the patient feels more welcome, his or her confidence in the group is boosted and information relevant for treatment which, for whatever reason, had not been transmitted earlier, can be revealed. These meetings have demonstrated both the limitations and the potential of formal medical consultations. They also support the view of the biopsychosocial model regarding multidisciplinary approaches as the way forward in terms of the changes in behaviour and lifestyle, which are so vital when treating chronically ill patients. The family is the third side of the so-called therapeutic triangle (doctor, patient and family) and plays an active role throughout treatment by providing a possible link between, or an ally of, the doctor and the patient. Family support has a direct influence on adherence to treatment, as does monitoring the correct use of medication and the identification of early signs of clinical relapse. For this reason, family members should receive the same guidance as the patient. On the other hand, family members who deal directly with the patient also need to be given special attention by the team, as they may be emotionally overloaded. The presence of the family during consultations and group meetings is of fundamental importance for the patient's course of treatment. This allows for information brought by the family to influence the approach to treatment, and also enables family members and the family as a whole to understand the way the disease affects them. For this reason, a stable, harmonious family unit, whose members are prepared to help one another, is a great stabilising factor for the patient. On the other hand, obviously dysfunctional families may trigger recurrence of the disease (Caprara \& Franco 1999).

\section{The Pernambuco Association of Chagas disease and Heart Failure Patients}

Set up in 1987, under the slogan "A Commitment to Life", the Pernambuco Association of Chagas and Heart Disease Patients has been providing social support for such patients. The Association is a non-profit organisation unconnected to any political party, with a board of directors made up of patients elected at an Assembly. It was recently recognised as a "Useful Institution" (28 December 2008). Its aim is to carry out social actions, 
with the participation of volunteers, who provide social support for patients with Chagas and Heart Disease. The Association holds meetings to clear up doubts regarding prevention, treatment and follow-up for such patients. Its work in the community is to provide information about various aspects of the disease, such as pacemaker and cardiodefibrillator implants and so forth, and to counter myths and stigmas attached to patients with Chagas disease. Among the various forms of social action, the Association provides medicine and basic foodstuffs for the neediest patients. Action is based on a database containing information on the socio-economic conditions of each patient and funding comes from the participation of contributing partners, donations from individuals and organisations (e.g., Sector Councils, Service Clubs and sometimes pharmaceutical labs that are prepared to donate medicines) and from holding events to sell clothes and second-hand goods, in addition to the sale of promotional materials (t-shirts, badges, caps and the like) at medical and scientific events. Efforts, albeit initial, have been made to find alternatives through training patients, by teaching them to read and write or to provide handicraft classes, with a view towards finding them a place in the employment market. Educational materials include leaflets and manuals that use clear and accessible language and that aims to counter commonly held erroneous beliefs regarding the disease.

Although it faces many challenges, the Association plays a vital role in the lives of Chagas patients and the experience has served as an example for other similar institutions in Brazil and overseas. The support of various sectors of the press has allowed the Association to make the general public aware of the disease and to understand it better, in addition to helping in the recruitment of volunteers.

For the above reasons and on the basis of the accumulated experience of the past 22 years, we believe in and defend our proposal for all-around patient care, including the full set of biological, psychological and social factors. Our proposal to provide a more humane form of care requires the involvement of all professionals and a deep commitment to the patient as a person. The main characteristic of humane health care is its ability to combine technical competence with the ability to deal with human beings.

\section{ACKNOWLEDGEMENTS}

To the Chagas Disease and Heart Failure Outpatient Clinic team, for their exceptional spirit of cooperation and commitment to the patients, to the Pernambuco Association of Chagas Disease Patients, for its dedication and constant work in upholding the civil rights of Chagas disease patients.

\section{REFERENCES}

Briceño-Leon R 1990. La casa enferma, sociología de la enfermedad de Chagas, Fondo Editorial Acta Científica de Venezuela/Consorcio de Ediciones Capriles, Caracas, 149 pp.
Caprara A, Franco ALS 1999. Relação paciente-médico: para humanização da prática. Cad Saude Publica 15: 647-54.

Chagas C 1909. Estudo sobre a morfologia e o ciclo evolutivo do Schizotrypanum cruzi $\mathrm{n}$. gen. sp. Agente etiológico de nova entidade mórbida no homem. Mem Inst Oswaldo Cruz 1: 159-219.

Coura JR 1985. Doença de Chagas como endemia urbana. In JR Cançado, M Chuster, Cardiopatia chagásica, Ed. Fundação Carlos Chagas, Belo Horizonte, p. 327-355.

Coura JR 2007. Chagas disease: What is known and what is needed: a background article. Mem Inst Oswaldo Cruz 102 (Suppl. I): 113-122.

Dias JCP 2000. Doença de Chagas no novo milênio. Rev Pat Trop 29 (Suppl.): 229-239.

Dias JCP 2007. Globalização, iniqüidade e doença de Chagas. Cad Saude Publica 23 (Suppl.): 513-522.

Dias JCP, Briceño-Leon R, Storino R 1994. Aspectos sociales, econômicos, culturales y psicológicos. In R Storino, J Milei (org.), Enfermidad de Chagas, Doyma Argentina, Buenos Ayres, p. 525-560.

Dias JCP, Dias RB 1979. Aspectos sociais, econômicos e culturais da doença de Chagas. Ciênc Cult 31 (Suppl. 1): 105-111.

DNDi - Drugs for Neglected Disease Initiative 2008. [homepage on the internet]. Available from: www.dndi.org.br. [acessed on 5 Dec 2008].

Engel GL 1977. The need for a new medical model: a challenge for biomedicine. Science 196: 129-136.

Engel GL 1980. The clinical aplication of biopsychosocial model. Am J Psychiatry 137: 535.

Engel GL 1987. Physicians-scientists and scientist-physicians. Am J Med 82: 107-111.

Feinstein AR 1972. The need for humanized science in evaluating medication. Lancet 2: 421-423.

Fontes OL 1999. Educação biomédica em transição conceitual, UNIMEP, Piracicaba, $187 \mathrm{pp}$.

Oliveira Jr W 1991. Forma indeterminada da doença de Chagas. Implicações médico-trabalhistas. Arq Bras Cardiol 54: 89-91.

Oliveira Jr W 1997. Cardiopata Chagásico em situações especiais. In: JCP Dias, JR Coura (orgs.), Clínica e terapêutica da doença de Chagas: uma abordagem prática para o clínico geral, Editora Fundação Oswaldo Cruz, Rio de Janeiro, p. 299-320.

Oliveira Jr W 2005a. Relação médico paciente em cardiologia: um olhar psicossomático. Revista Sulmineira de Psicossomática 1: 41-46.

Oliveira Jr W 2005b. Atenção integral ao paciente chagásico: uma proposta para o cuidar. Arq Bras Cardiol 84: 1-2.

Siqueira JE 2002. A arte perdida de curar. Bioética 10: 89-106.

WHO - World Health Organization 2002. Control of Chagas disease. World Health Organ Tech Rep Ser 905: 1-109.

WHO - World Health Organization 2007. Global network for Chagas elimination. [Available from: www.int/mediacentre/news/ release/2007/pr-36/en/index/html]. 